\title{
Factors affecting the level of androstenone Michel Bonneau*
}

\author{
Address: UMR INRA Agrocampus Rennes SENAH, 35590 Saint Gilles, France \\ * Corresponding author
}

\begin{abstract}
from Prevention of Boar Taint in Pig Production: The 19th Symposium of the Nordic Committee for Veterinary Scientific Cooperation Gardermoen, Norway. 21-22 November 2005

Published: 7 August 2006

Acta Veterinaria Scandinavica 2006, 48(SuppI I):S7 doi:I0.II86/I75I-0147-48-SI-S7
\end{abstract}

(c) 2006 Bonneau.; licensee BioMed Central Ltd.

\section{Introduction}

As pointed out in Øystein Andresen's previous presentation, androstenone ( $5 \alpha$-androst-16-ene-3-one) is one of the major compounds responsible for boar taint. It belongs to the family of the 16-androstene steroids that are synthesized in the testis together with androgens and estrogens. The present paper borrows a lot of its content from previous reviews [1].

\section{Androstenone levels in entire male pig populations}

At usual slaughter weights fat androstenone levels are very variable between animals and distributed in a log-normal manner (Figure 1). The distribution of androstenone is more skewed than that of skatole, which means that a higher proportion of pigs exhibit high levels, on the right side of the distribution. Androstenone levels exceeding 1 ppm were found in $29 \%$ of the 4313 entire males measured by Walstra et al. [2] while $15 \%$ of them exhibited skatole levels higher than $0.2 \mathrm{ppm}$. Fat androstenone contents may vary quite extensively between pig populations as shown in the results of Walstra et al. [2] where the proportion of entire males with androstenone levels higher than $1 \mathrm{ppm}$ varied from $12 \%$ to $43 \%$ in 12 populations of entire male pigs ( 6 countries $\times 2$ seasons). The distribution of androstenone levels in the 2 extreme populations is presented in Figure 2.

\section{Biosynthesis, accumulation in fat and elimination of androstenone}

According to the scheme presented in Figure 3, fat androstenone content results from the balance between its synthesis and elimination. It does not seem to be related to its catabolism in the liver [3]. However, sulfoconjugation, that binds steroids to sulphate groups so that they can be eliminated, may be involved in the regulation of androstenone accumulation in fat [4].

The biosynthetic pathways of the 16-androstene steroids have been described by David Gower at Guy's hospital in London [5]. A simplified scheme is presented in Figure 3. The overall steroid synthesis is dependent on sexual maturity. The balance between 16-androstene steroids (with no hormonal action) and androgens and estrogens (responsible for the improved performance of the entire male compared to the castrate) depends on the activity of the enzyme complex andien- $\beta$ synthase. To achieve high rates of androstenone synthesis a pig has to be sexually mature and exhibit high andien- $\beta$ synthase activity.

\section{The effect of age and weight on androstenone levels}

The intensity of androstenone synthesis is low in the young piglet, and then increases steadily during the establishment of puberty $[6,7]$, concomitantly with the increase in production of the other testicular steroids, androgens and estrogens.

The well known high variability in sexual development is responsible for differences in the age when the elevation in steroid levels occurs, whereas differences in the potential for androstenone production are responsible for the magnitude of the elevation $[8,9]$. The scheme presented in Figure 4 shows that, at usual slaughter stages, only animals having both early sexual maturation and high potential for androstenone production exhibit high androstenone levels. Increasing slaughter weight results in more animals being sexually mature and expressing their potential for androstenone production. However, correlations between fat androstenone level and slaughter weight 


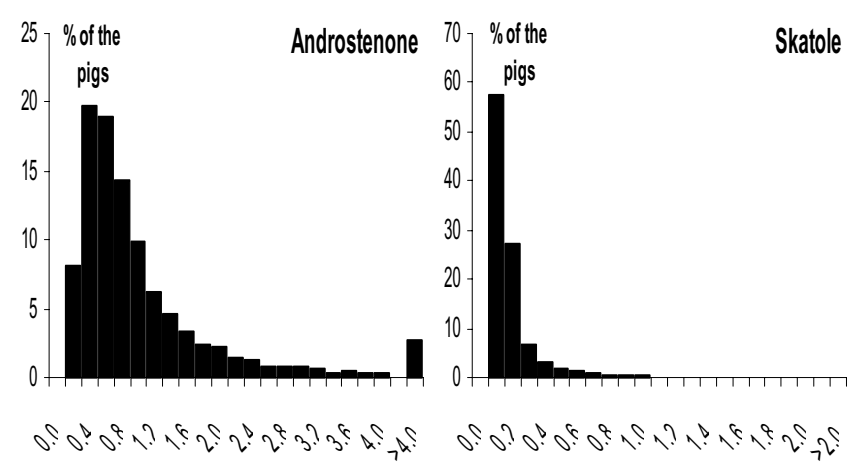

Figure I

Distribution of androstenone and skatole levels in 4313 entire male pigs from 6European countries (after Walstra et al. 1999).

are low (e.g. Walstra et al. [2]). Indeed, even when all animals are sexually mature, there is still a lot of variability originating from differences in potentials for androstenone synthesis and elimination.

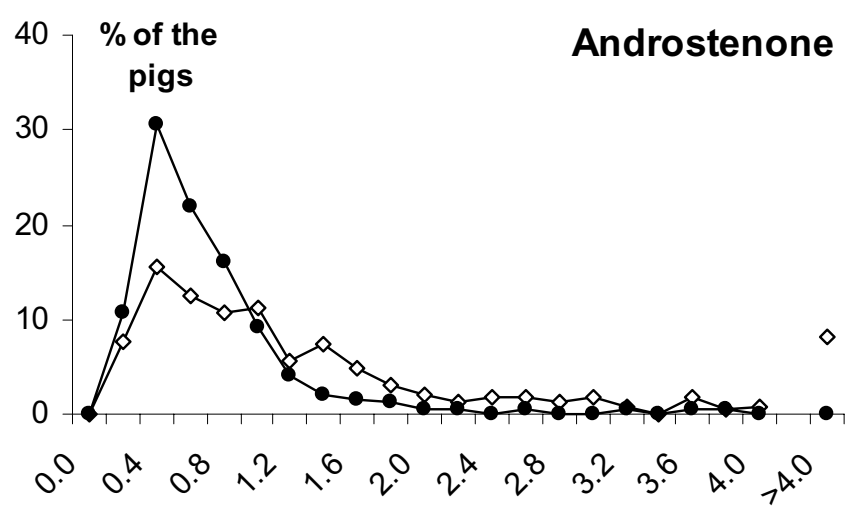

Figure 2

Distribution of androstenone levels in two entire male pig populations (after Walstra et al. 1999).

\section{Management factors affecting androstenone levels}

Management factors affecting sexual maturation have some, but little, effect on fat androstenone levels. Social

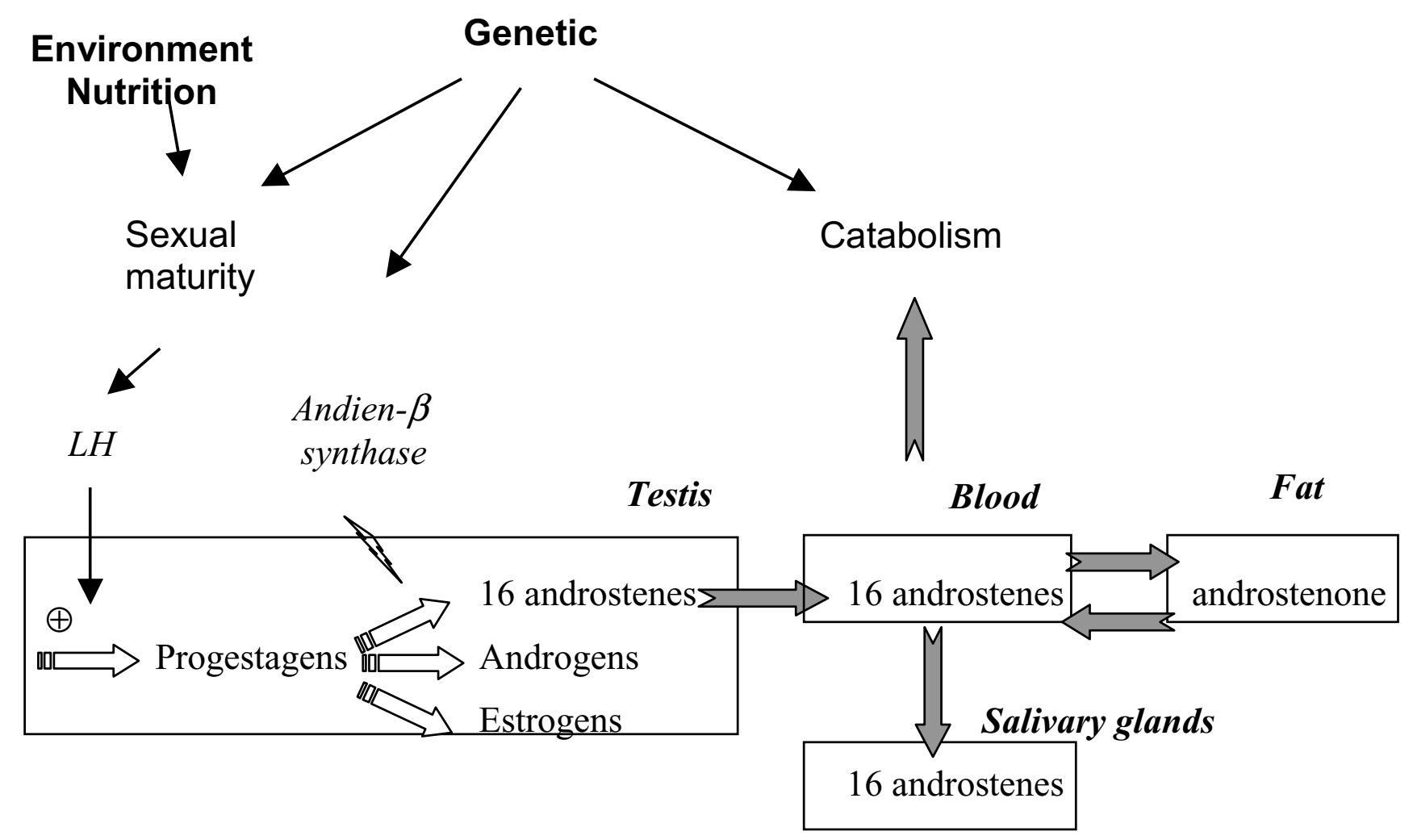

Figure 3

How genetics, environment and nutrition can affect fat androstenone levels. 


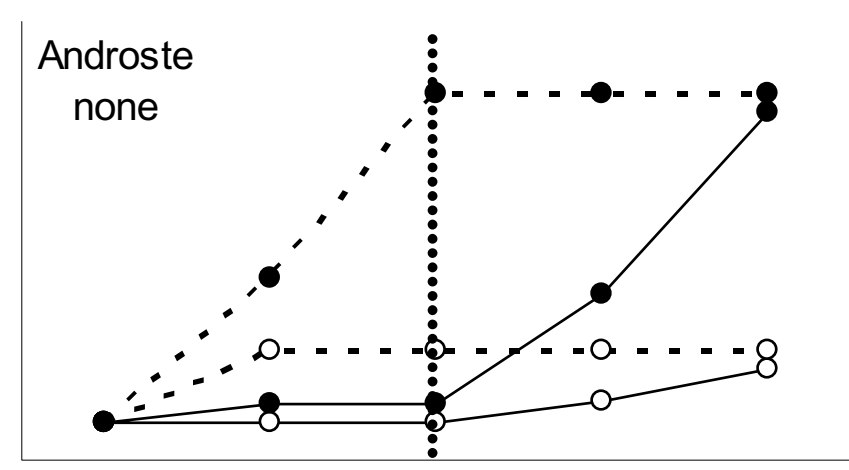

Age/Weight

Figure 4

A scheme for the development of androstenone levels in early (broken lines) or late (solid lines) maturing pigs exhibiting high (black circles) or low (open circles) potential for androstenone production. The vertical line indicates the usual slaughter stage.

factors do not have consistent effects. However, "birth to slaughter" systems, avoiding the mixing of unrelated animals, seem to result in lower androstenone levels [10]. Photoperiod has a limited influence on androstenone levels, decreasing day length resulting in earlier sexual maturity and slightly higher androstenone levels [11]. High energy feeding is associated with acceleration of pubertal development and increased androstenone levels [12,13].

\section{Genetic factors affecting androstenone levels}

Fat androstenone levels are mostly dependent on genetic factors affecting sexual maturation, potential for androstenone synthesis and, possibly, androstenone clearance (Figure 3). This will be developed in Jim Squires' presentation later on today.

\section{Conclusion}

Drastic reductions in androstenone contents have to be achieved in order to get boar taint free meat. Management factors have a very limited impact on androstenone levels, in contrast with skatole. The required drastic reduction in androstenone levels can be achieved only with very efficient methods.

A first approach is to select animals with a low potential for androstenone accumulation in fat (see presentation by Jim Squires). The advantage is that androgen and oestrogen steroid production may be kept at a sufficient level to benefit from the better feed efficiency and higher leanness of the entire males. The drawbacks are that boar taint related to substances other than androstenone is not affected.
The second approach is to eliminate or reverse sexual development (EFSA, 2004 [14]). This can be achieved via i) down regulation of the hypothalamic-pituitary-gonadal axis by exogenous hormones (not an option in the EU), ii) castration with chemicals (not sufficiently investigated so far) or iii) Immunocastration (see presentation by Stig Einarsson). The advantage is that all boar taint substances are affected, the drawbacks are that all or part of the better performance associated with entire males is lost.

\section{References}

I. Bonneau M, Squires E): Use of entire males for pig production. I Conferencia Virtual Internacional sobre Qualidade de Carne Suína [http:I Iwww.cnpsa.embrapa.br/home.en.html.]. 16 November - 16 December 2000

2. Walstra P, Claudi-Magnussen C, Chevillon P, von-Seth G, Diestre A, Matthews KR, Homer DB, Bonneau M: An international study on the importance of androstenone and skatole for boar taint: levels of androstenone and skatole by country and season. Livest Prod Sci 1999, 62:15-28.

3. Babol J, Squires EJ, Lundström K: Relationship between metabolism of androstenone and skatole in intact male pigs. J Anim Sci 1999, 77:84-92.

4. Sinclair PA, Squires EJ: Testicular sulfoconjugation of the 16androstene steroids by hydroxysteroid sulfotransferase: its effect on the concentrations of 5 alpha -androstenone in plasma and fat of the mature domestic boar. J Anim Sci 2005, 83:358-365.

5. Gower DB: $\mathbf{1 6}$ androstene steroids: a review of their chemistry, biochemistry and possible physiological role. J Steroid Biochem 1972, 3:45-103.

6. Andresen $\varnothing$ : Concentrations of fat and plasma 5a-androstenone and plasma testosterone in boars selected for rate of body weight gain and thickness of back fat during growth, sexual maturation and after mating. J Reprod Fertil 1976, 48:5I-59.

7. Claus R: Pheromone bei Säugetieren under besonderer Berücksichtigung des Ebergeruchstoffes und seiner Beziehung zu anderen Hodensteroiden. Z Tierphysiol Tiernähr Futtermittelkd 1979, 10:316.

8. Bonneau M, Carrie-Lemoine J, Prunier A, Garnier DH, Terqui M: Age related changes in plasma $\mathrm{LH}$ and testosterone concentration profiles and fat 5-alpha-androstenone content in the young boar. Anim Reprod Sci i 1987, I 5:24I-258.

9. Bonneau M, Carrie-Lemoine J, Mesure-Morat M: Genital tract development and histomorphometrical traits of the testis in the young boar: relationships with fat 5 alpha -androstenone levels. Anim Reprod Sci 1987, I 5:259-263.

10. Fredriksen B, Nafstad O, Lium B, Marka C, Heier B, Almaas C: The effect of group composition on the levels of androstenone and skatole in entire male pigs. In From the Proceedings of the EAAP Working Group on Production and Utilisation of Meat from Entire Male Pigs Dublin, Ireland. 13-14 November 2003

II. Andersson H, Wallgren M, Rydhmer L, Lundström K, Andersson K, Forsberg M: Photoperiodic effects on pubertal maturation of spermatogenesis, pituitary responsiveness to exogenous GnRH, and expression of boar taint in crossbred boars. Anim Reprod Sci 1998, 54:121-137.

12. Øverland M, Berg J, Matre T: The effect of feed and feeding regime on skatole and androstenone levels and on sensory attributes of entire male and female pigs. In From the Proceedings of the EAAP Working Group Production and Utilisation of Meat from Entire Male Pigs Milton Keynes, UK. 27-29 September 1995

13. Zeng XY, Turkstra JA, Jungbloed AW, van Diepen JThM, Meloen RH, Oonk HB, Guo DZ, van de Wiel DFM: Performance and hormone levels of immunocastrated, surgically castrated and intact male pigs fed ad libitum high- and low- energy diets. Livest Prod Sci 2002, 77: I-II.

14. EFSA: Welfare aspects of the castration of piglets. European Food Safety Authority report AHAW/04-087 2004 [http:// www.efsa.eu.int/science/ahaw/ahaw opinions/5/2 en.html.]. 